
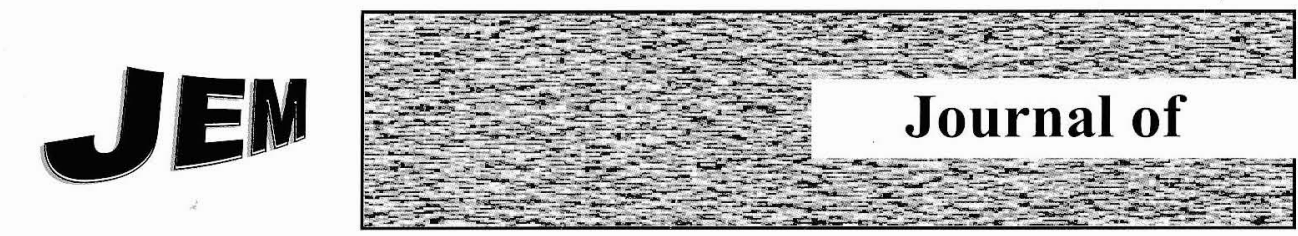

EDucational Management

A Bi-annual Publication of

THE INSTITUTE FOR EDUCATIONAL PLANNING AND ADMINISTRATION

(IEPA)

University of Cape Coast, Ghana

ISSN 0855 - $3343 \quad$ Vol. $6 \quad$ Nov. 2012 


\title{
Managing Transitional Challenges for Quality Performance in Polytechnics in Ghana
}

\author{
Fanny Ama Darkey, \\ George K.T. Oduro
}

\section{Abstract}

This paper presents the findings of a study into transitional challenges facing polytechnic management in Ghana, effects of those challenges on the quality delivery of polytechnic education and how polytechnic management was managing such challenges. The research was a descriptive survey involving 340 respondents drawn from 6 polytechnics in Ghana. Respondents included both senior members and senior staff. Data were gathered through questionnaire and interviews. Informed by the study, the paper agues that the management of polytechnics encounter a number of challenges, some of which are easily manageable whilst others require strategic management skills to address. It further advocates a stronger collaboration between the polytechnics and industry as a way of promoting quality competency-based training in the country.

\section{Introduction}

The important role tertiary education and for that matter polytechnic plays in the life of individuals and nations, especially, countries within the developing context cannot be underestimated. It is noted that many industrialized countries recognize technical manpower development as a powerful agent for economic growth and so such countries have a welldeveloped polytechnic education to support the technical manpower for all sectors of the economy (Report of the Technical Committee on Polytechnic education in Ghana (2001).

In this era of globalization, characterized by rapid advancement of science and technology, there is the need for effective management of polytechnic education to enable the polytechnics meet the middle level manpower needs of the society. Indeed, as Afeti (1998) observes, any nation that fails to recognize the essential role Science and Technology and for that matter polytechnic plays in the era of globalization and socioeconomic transformation of nations cannot escape the clutch of poverty.

The Government of Ghana, realizing the socio-economic significance of polytechnic education in the country, made polytechnic education part of the tertiary education system and mandated polytechnics to train highskilled manpower to support industrial development in the country. University Rationalization Committee, (1988), reviewed the then tertiary education system to include the polytechnics. Prior to1988, polytechnics were classified as Second cycle institutions. They operated as Technical Institutes which offered mostly technical level courses with an objective to train students in specific trades and vocation disciplines. 
The laws establishing the polytechnics (PNDCL 321 of 1992) stipulated the aims and objectives of polytechnics in the country to include the provision of tertiary education through full time courses in manufacturing, science and technology, applied arts and sciences and other areas as would be determined from time to time. The law also gave legal backing to changes involving administration, the polytechnic structure, courses, and certificates and staffing and placed the polytechnics under the country's National Council for tertiary Education (NCTE) with some degree of autonomy. Within this context, the polytechnics were given the go-ahead for new set-ups to be put in place so that they could complete the cycle of capacity strengthening for higher level technician training and practical research which did not exist in the old system. Currently, with the enactment of the Polytechnic Act, 2007, (Act, 745) the polytechnics have the academic autonomy to among other things award their own Higher Diploma and other certificates.

The upgrading of some polytechnics from second cycle status to tertiary status signifies a change from one stage unto another. This type of change or transition, according to Jackson and Schuler (2001), refers to any transformation in the structure or functioning of an organization. Change begins with someone recognizing the need for it and is usually triggered by an external force, (Mcshane and Von Glinow (2000). In the case of the polytechnics, for example, change in their status as brought with it a number of management challenges relating to institutional and professional development, particularly staffing.
The change (upgrading) from secondary to tertiary status required that the polytechnics recruited individuals with relevant practical or professional experience to train students who could contribute to the development of the industrial and technological base of the economy. This confirms Kreitner and Kinicki's (2000) assertion that during change processes in institutions, people with outdated skills are often retrained, unemployed or underemployed to meet the challenges that go with it. To this end, the few Ghana Educations Service staff who initially handled the second cycle courses and opted to teach in the polytechnics were screened and retained. Since then, most of the polytechnics attempted to step up staff development which is in the right direction as part of the recruitment process. It is worthy to note that, the Polytechnics are now using the National Council for Tertiary Education (NCTE) criteria as bases for recruiting and designating academic staff to beef up staff strength in the polytechnics. This criterion makes second degree (MSC or MPhil degree) the minimum qualification for recruiting a lecturer.

The transitional changes have affected the physical and academic infrastructure of the polytechnics (The Education Review Committee Report (2002), Technical Committees' Report on Polytechnic education, 2001), compelling some of them to run programmes late into evening hours especially for practical work. As a way of addressing these challenges, efforts have been made to improve the governance and management structures of the polytechnics through the appointment of qualified rectors and senior management staff (Afeti 2004). 
With the enactment of the Polytechnic Act 2007, (Act, 745) polytechnics in Ghana now have academic autonomy to carry out their academic activities to the fullest. The polytechnics, over the past decade, endeavoured to meet transitional challenges which are attributed greatly to the way they were upgraded to the tertiary status without a thorough analysis of their capacity to fulfill their mandate as tertiary institution. It is observed that, within the relatively short period, of their upgrading modest achievement have been chalked in the areas of autonomy in management of the institution, strengthening of academic programmes to include the Bachelor of Technology (degree programmes) and upgrading of teaching and learning facilities to some extent.

\section{The Problem}

There have been reports such as the (Report of the Technical Committee on Polytechnic education in Ghana (2001), and Educational Reform Review Report (2002) that because the polytechnics were upgraded without any endowment fund for their physical and academic infrastructure, they are faced with some challenges as far as delivery of quality polytechnic education is concerned. Afeti (2005) has also reiterated that the approaches to the upgrading exercise did not specify any criteria or qualifying benchmarks in terms of physical, human and academic resources. This is one of the flaws in the entire upgrading process which is posing a lot of challenges for the polytechnics today. Rectors of some polytechnics have been emphasizing in their ceremonial reports that they are faced with numerous challenges regarding the inadequacies in the provision of resources which are impacting negatively on the effective delivery of polytechnic education.

Undoubtedly, for them to achieve the demand of their mandate as tertiary institutions, polytechnics had to grapple with management challenges relating to availability of how they are able to cope with the challenges. Available literature hardly, however, tells us how polytechnics effectively manage those challenges in order to achieve the objectives for which they were elevated to a tertiary status. It was as a result of this that this study was carried out to find out how the polytechnics in Ghana are managing their transitional challenges. The research was guided by the following three key questions:

1. What key management challenges have the polytechnics in Ghana faced since their upgrading into tertiary status?

2. What are the views of respondents on the effects of those challenges on polytechnic education?

3. What strategies are being adopted to enable the polytechnics manage those challenges?

\section{Methodology}

The research was descriptive by nature. It involved three hundred and forty (340) respondents drawn from six (6) polytechnics in Ghana using mixed-sampling methods. The respondents were made-up of both senior members and senior staff (comprising the teaching and nonteaching staff). Other respondents were the then Principals and VicePrincipals. The main instruments used 
were the questionnaire designed for the teaching and non teaching staff and interview guide for Rectors and the Vice Rectors. Both instruments were tested for validity and reliability prior to the actual data collection.

The major statistical tools employed for the interpretation of the data collected were frequencies and percentages using the SPSS soft ware packages. A non-parametric test Kendall's W' Test otherwise referred to as Co-efficient of Concordance was also used to test the level of agreement in ranking of the various challenges faced by polytechnics in Ghana. In addressing the objectives of the study, the following overarching questions informed the research.

\section{Emerging Issues}

A major finding of the study is that polytechnics in Ghana are confronted with myriads of management challenges. Among these are insufficient number of qualified staff, inadequate funding to support programme delivery, and inadequate physical and academic facilities which cut across in all polytechnics used for the study. Absence of distinct scheme and condition of service for staff, lack of active collaboration with industries and lack of regular review of the existing curriculum to reflect current demands of the job market were other challenges.

The issue of inadequate staff for instance, corroborates Aina's (2000) finding that one of the challenges facing all levels of education in the sub-Saharan Africa, especially the polytechnics is inadequate qualified staff which has negative implication on teaching and learning and quality of polytechnic graduates. It is further explained that this problem could link up with the challenge of inadequate funding which inhibit the development of technical manpower as cited in Adeyemi and Uko-Aviomoh (2004) report. In the seventh matriculation report by the Rector of the Bolgatanga Polytechnic, he reiterated that inadequate funding is a challenge to the Polytechnic and that the policy of of allocating resources to the tertiary institution especially the polytechnics on the basis of student population was inimical to the growth of some institutions such as the Bolgatanga Polytechnic. Afeti (2005) supported the issue of under funding by indicating that no credible practicallyoriented learning can take place if the polytechnics do not have adequate qualified teachers to handle the large number of learners in skills acquisition.

Polytechnics are again confronted with a challenge that is traceable to high ratios observed for training in management disciplines that has been the trend in most African countries including Nigeria and Ghana. Adeyemi and Uko-Aviomoh (2004) in their study identified a situation whereby most applicants to the Polytechnic prefer management disciplines so as to eventually work in the banks, insurance companies, oil companies which they pay better than most sectors. The Polytechnic thus admit student irrespective of the rules guiding admission and available resources including teachers. Afeti has confirmed that about $60 \%$ of Polytechnic students are enrolled in business oriented programmes, a situation that does not promote the development of skilled manpower for the country. He further added that in 
contrast, government policy on admission requires that the Polytechnic enrollment should attain the ratio of 80 is to 20 in favour of science and technology.

Even though the polytechnics were upgraded to contribute immensely towards national development by providing career-focused education and skills training to the highest level possible, the polytechnics in their bid to generate additional income to supplement government subventions are concentrating on providing more non-tertiary programmes to the detriment of the HND programmes which they had been mandated to offer as tertiary institutions. This to the researcher is another challenge being faced by the polytechnics.

On the whole, workers in the polytechnics recognize the key challenges confronting polytechnics as they work towards providing quality education. The mean percentage ratings on the nature of the challenges revealed that, the most cross-cutting serious challenges confronting the polytechnics were inadequate human and material resources, inadequate funding and inadequate physical and instructional facilities. This Collaborates, Afeti's (2005) disclosure that, in Ghana, the rapid increase in student numbers without expansion in teaching and learning facilities in the polytechnics has led to unacceptably high studentlecturer ratio, in some cases, as high as 54.1. The mean of means ranking of the responses showed that while some of the challenges were considered most serious in some polytechnics, others were considered least serious. In Accra, Ho, and Kumasi Polytechnics for instance, absence of distinct scheme and conditions of service was considered most serious; yet in the other polytechnics these challenges were considered least serious.

The challenges with which the polytechnics grapple, have adversely affected teaching and learning over the years. For instance, inadequate funding had stifled the development of some departments within the polytechnics. Views expressed by $60 \%$ of the staff suggest that inadequate provision of physical and academic facilities had impacted negatively on programme delivery and quality of polytechnic education. On a more positive note, the study revealed that strike action by the staff to press home their demand for better conditions of service had resulted in improved working conditions to some extent. This finding accords with what Adesina (1990) reported that persistent efforts by teachers to improve their working conditions often improve the conditions to some extent though there is room for more improvement.

Polytechnic education demands active collaboration with industry. Yet, the study showed lack of active collaboration between the polytechnics and industries in Ghana. This has indeed adversely affected the quality of polytechnic products over the years. Indeed the challenges enumerated above impact negatively on teaching and learning and the effective delivery of polytechnic education in the country.

\section{Coping Strategies}

In an attempt to address the challenges, some rectors have adopted varied management strategies. One strategy 
that addressed the challenge of inadequate qualified staff and their retention was the implementation of staff development policies through granting study leave with pay to staff members to upgrade their skills and knowledge in relevant fields of study. Apart from that, the polytechnics are accessing scholarships from other sources to support further studies of, particularly teaching staff both locally and abroad. This strategy also aims at motivating existing staff and consequently attracting others into the polytechnics. The capacity strengthening strategies of management, however, have come with another dimension of challenge: how to retain trained staff in the polytechnic. Seventy five percent of respondents, for example, suggested that some polytechnics were faced with the challenge of losing their staff to the universities, which are comparably paid higher than the polytechnics, once they are sponsored by polytechnics to pursue and complete their studies.

Within the context of scarce resources, some polytechnics have adopted the strategy of granting concessionary loan facilities for the purchase of, for example, vehicle and paying rent advance as ways of retaining trained staff in the polytechnics. However, some staff have often been dissatisfied with the quantum of loans available for them. It is in this context that the Education Reform Review Committee (2002) recommended that by way of attracting and retaining highly qualified staff in the polytechnics, government, should assist polytechnics in granting such loan facilities to polytechnic staff. Further more, the polytechnics have been advised to take advantage of the financial provisions under the Ghana
Education Trust Fund (GETFund) to improve post graduate training by way of upgrading the existing staff and to attract more qualified ones. This strategy was to help the polytechnic to compete with the industry in recruiting qualified and experienced staff.

It has been observed that by means of addressing the challenge of underfunding, the polytechnics have embarked on income generating activities which include organizing non-tertiary programmes apart from the mandated HND programmes. Other incomes are accrued from fees paid by both foreign and local students in some polytechnics. Other departments in some polytechnics render aspects of commercial and consultancy services to generate income. Although such activities are geared toward generating additional income besides the government subsidies, on the whole, little had been done in the areas of consultancy services and soliciting financial assistance from donor and corporate agencies.

In terms of improving the physical infrastructure, it was observed that almost all polytechnics had sought support from the GETfund. Visits to the polytechnics showed that there had been facelifts in the polytechnics in recent times in terms of lecture halls, laboratories, libraries among others.

As a strategy to develop active collaboration with the industries, the polytechnics engage their students in industrial attachment at the industries as part of their training. On the part of the teaching staff, only few of them encourage their staff to undergo the practical training in the industries. It is realized that collaboration with the 
industries had not been fully explored though practical training is a prerequisite in the formation of polytechnic graduates. More so, no formal agreement exists between the polytechnics and industries to promote industrial component of the training.

\section{Conclusion}

So Far, The Discussion Has Focused on the important role played by polytechnic education toward technological development of the country. Achieving the goals of the polytechnics require a new style of management who can place staff welfare at the centre of all managerial activities. By so doing, they will be able to reduce the level of trained staff attrition at the polytechnic level. Such a strategy was crucial because without the retention of highly trained teaching staff, it will be very challenging for the polytechnics to carry out their mandate to train careerfocused middle level personnel which are particularly critical for the effective implementation of decentralization policies and planning reforms.

Particular attention should be paid to the challenges confronting the management of polytechnics as they transit from secondary to tertiary education levels. Without efficient and effective management of such transitional challenges, polytechnics would be hindered from performing their roles as mandated. At the institutional level, rectors, deans and heads of department need to commit themselves to instituting strategies towards augmenting government efforts since single source of managing the challenges could be frustrating, and perhaps, more difficult to achieve. Industrial liaison sections of the polytechnic should also be strengthened and empowered to function more effectively so that they could establish stronger links with industry to support their (polytechnics) development plans.

\section{Implications for management practice}

1. Developing leadership and management capacity of Rectors, Deans and Heads of Department.

The challenges facing polytechnics and the strategies needed to cope with such challenges have implications on the management and leadership capacity development of Rectors, Deans and Heads of department. Special attention should therefore be given to the training of such people in leadership and manage-ment to enable them understand the issues involved in transitional challenges and ways of managing them. It also has implications for the recruitment strategies and other related management-related practices in the polytechnics.

2. Attracting and Retaining High Calibre Staff

To attract more qualified staff to polytechnics, it is essential that management persistently dialogues and negotiates with the government to establish a more competitive salary structure as well as better conditions of service for staff. This would go a long way to boost their morale for work. Management of the polytechnics should recognize 
that staff are the most important resource hence must adopt personnel policies which are geared towards recruiting workforce that have the requisite skills and knowledge to produce quality graduates. Above all, the staff must be supported to be abreast with new development and changes in their areas of expertise.

\section{Enhancing Institutional and Staff Capacity}

In terms of enhancing the capacity of staff, the management of polytechnics should explore other avenues for funds to support staff training and development without relying solely on the Government's GETFund scholarship. Theycould also think about ways of increasing internally generated funding sources to enable them augment what the government grants through the GETFUND. Such internally generated funds could also support the provision of infrastructure and maintaining existing ones to promote teaching and learning.

\section{Managing Curricular Activities}

Considering the practical nature of polytechnic education, management has the task of providing effective leadership towards promoting competency-based teaching and learning in the polytechnics. Strategies should be adopted such as forging formal and mutual beneficial links with business and industry to support their programmes. Such initiative could come from the
Rectors, Deans and Heads of Academic Departments.

\section{Enhancing Industrial Attachment}

Industrial attachment should not be only restricted to students but it is necessary for polytechnic teachers to also undergo practical training on holidays to update their knowledge and skills as well as acquaint themselves with new trends in industry. The various Liaison offices should be provided with the necessary logistics to ensure effective industrial attachment training and supervision. Management should ensure that well documented programme regarding students' attachment are forwarded to the industries for them to be abreast with polytechnic attachment procedures as away of establishing links with the industries.

\section{Improving Physical Infrastruc- ture}

With regard to improving academic and physical infrastructure, management of the polytechnics are to explore more avenues and above all impress upon the Government to ensure that those facilities are expanded so that the polytechnics could discharge their roles for which they were upgraded. Since not all polytechnics have the capacity to provide certain infrastructure using their internally generated funds, management could contact some institutions like the World Bank to recommend other means of soliciting for funds to provide physical and academic facilities. 
6. Enhancing Access to Financing Arrangement

To improve upon access to funds in the polytechnics, management could task Head of Departments to come out with income generating proposals and other road maps to generate additional income apart from the existing ones, that is, running of more programmes. The Vocational/Technical departments could use their expertise to engage in more consultancy services as well as render commercial services to the communities for more income. Management could liaise with industries and other organizations to solicit financial assistance.

\section{References}

Adesina, S. (1990). Educational management. Enugu, Nigeria: Fourth Dimension Publishing Co. Ltd.

Adeyemi, J. K. \& Uko-Aviomoh, E. (2004). Effective technology delivery in Nigerian polytechnics: Need for academic manpower development policy. Education Policy Analysis Archives, 12 (24). Retrieved (27/09/ 2004) from htpp://epaa.asu. edu/epaa/v12n24/.

Afeti, G. M. (1998, December 10). Vision 2020: The role of polytechnics. Daily Graphic (No. 147476), p.7.

Afeti, G. M. (2004). Promoting change and innovation in tertiary education. experience of Ho Polytechnic. Ghana: NCTE pp.1-15 www.worldbank. org/afr/ teia/conf 0903/george afeti. Retrieved May 5, $\overline{2} 005$

Afeti, G. M. (2005, April 13): A decade of polytechnic education in Ghana I. Daily Graphic (No.149402), p.11.

Afeti, G. M. (2005, April 15). A decade of polytechnic education in Ghana II. Daily Graphic (No. 149404), p. 17.

Afeti, G. M. (2005, April 18). A decade of polytechnic education in Ghana III. Daily Graphic (No.149406), p. 17.

Aina, O. (2000). Nigeria technical and vocational education in the near future: Vision and action. Abuja, seminar proceedings.5-14.ASSUA (2003). This government has failed us, The Guardian. Wednesday, 6.

Ghana Government (1992). Polytechnic Law, PNDC L 321: The Ghana polytechnic statutes. Accra, Ghana: Author.

Government of Ghana, Polytechnic Law 1992, PNDC Law 321 (January 1993).

Jackson, S. E. \& Schuler, R. S., (2001). Managing human resources: A partnership perspective. USA: South Western College Publishing.

Kreitner, R. \& Kinicki, A. (2001). Organizational behaviour: ( $5^{\text {th }}$ ed.). New York: Irwin / McGraw-Hill Companies.

Mcshane. S. L. \& Von Glinow, M. A. (2000). Organizational behaviour. USA: Mc Graw Hill Companies. 
Ghana. (3), N.C.T.E.

Ministry of Education and Culture (1998) University Rationalisation Study, Volume II, Final Report. Accra: Ministry of Education and Culture.

National Council for Tertiary Education. (2001). Report of the technical committee on polytechnic education in
Report of the education reform review committee in Ghana. (2002). Legon- Accra: Adwinsa Publications GH, Ltd.

White paper on the education reform review committee. (2004). Ministry of Youth and Sports. Ghana. 